tions is that the theory of general static equilibrium is not only of importance in itself but also serves as "a powerful apparatus for dynamic analysis . . . by offering deep insight into the reaction of representative consumers and entrepreneurs to given situations ... and through the process of model construction, it paves the way to econometric research" (author's preface, p. xii). There are chapters towards the end of the book, simple and even sketchy though they may be, which introduce the student to stability conditions, to money, risk and uncertainty, and to the stochastic approach in econometrics.

On the other hand, though Prof. Fossati has written with recent developments in economic theory in mind, the text remains a version of the scheme originally elaborated more than ten years ago. It cannot be expected, therefore, that the analysis is completely up to date, still less that it should emphasize those particular lines of thought most familiar to AngloAmerican economists. Indeed, Keynes gets no more than one incidental mention and Leontief none at all; nor is the 'linear programming' school represented. In fact, following Pareto, the treatment is strictly confined to continuous analysis of the familiar marginal type, easily expressible in terms of the calculus.

The mathematics, it should be noted, are largely relegated to appendixes to the various chapters. The exposition is designed to be simple, clear and lucid, and it succeeds admirably. There are adequate lists of books and articles to assist the student in his further reading.

R. G. D. Allen

\section{LIPID BIOCHEMISTRY}

The Lipids

Their Chemistry and Biochemistry. By Prof. Harry J. Deuel, Jr. Vol. 3 : Biochemistry-Biosynthesis, Oxidation, Metabolism, and Nutritional Value. Pp. xxxvi + 1065. (New York: Interscience Publishers, Inc.; London: Interscience Publishers, Ltd., 1957.) 25 dollars.

THE late Prof. H. J. Deuel set himself to write a single treatise on the chemistry and biochemistry of lipids and with the apperance of this third volume his monumental task is complete. Volume 1 describes the chemistry of the lipids (Nature, 170,727 ; 1952) and Volume 2 desls with some aspects of their biochemistry : digestion, absorption, transport, and storage (Nature, 177,$1050 ; 1956$ ). The present volume covers other aspects of lipid biochemistry, in particular biosynthesis, oxidation, metabolism, and nutritional value.

After a brief introductory chapter, three chapters (266 pp.) are given to an account of the biosynthesis, oxidation, and metabolism of fatty acids, glyoerol, and the triglycerides. Then come chapters on the oxidation and metabolism of phospholipids and their hydrolysis products (18 pp.), on the role of formic, acetic, and propionic acids in fat metabolism (38 pp.), and on the metabolism of branched-chain acids, hydroxy- and keto-acids, di- and tri-basic acids, acid amides, aldehydes, and hydrocarbons (70 pp.). There follows an account of the metabolism of cholesterol and related sterols ( $60 \mathrm{pp}$.), the carotenoids and vitamins $A$ (200 pp.), vitamins $D(62$ pp.), vitamins $E$ (68 pp.) and vitamins $K(32 \mathrm{pp}$.$) , and the final$ chapters are devoted to the essential fatty acids (52 pp.) and the nutritional value of fats (99 pp.).
The book has three indexes covering $130 \mathrm{pp}$. Each topic is covered in the same comprehensive and impartial manner which the author has displayed in earlier volumes. More than five thousand references are listed including several to publications in 1956, and only very few trivial errors have been noted in the text.

Prof. Deuel had prepared the text of this volume before his death in 1956, so that, although his colleagues and friends assisted in the later stages of publication, the book remains his. With its companion volumes it will long be a standard work in this field and a tribute to H. J. Deuel's zeal, industry, and enthusiasm. The text is prefaced by a biograph. ical note about the author written by George $R$. Cowgill.

F. D. GUNSTONE

\section{ENGINEERING THERMODYNAMICS}

\section{Engineering Thermodynamics}

Work and Heat Transfer. By G. F. C. Rogers and Y. R. Mayhew. Pp. $x+619$. (London: Longmans, Green and Co., Ltd., 1957.) 50s. net.

THE authors have succoeded in providing the first English publication (rather than English republication of works by American authors) to give a rigorous treatment of fundamental and applied thermodynamics for the engineering student.

The first section discusses the principles of thermodynamies, and here the authors wisely follow the lines of Keenan's "Thermodynamics". They have amplified and added to Keenan's presentation. (For example, they discuss the statement of the second law for a control surface.) In general a simple lucid survey of basic thermodynamics is given, although in the discussion of the thermodynamic scale of temperature rigour has been sacrificed in the attempt to simplify the presentation.

A second section discusses "Application to Particular Fluids". Properties of fluids, non-flow and flow processes, power and refrigeration cycles, properties of mixtures and combustion processes are logically dealt with in a readable yet rigorous fashion. The section on foed heating is not as good as other parts of the book, the distinction between direct contact and surface heating not being adequately developed.

Components used in thermodynamic cycles are discussed in two sections on work and heat transfer. In their discussion of turbo-machinery, the authors point out the limitations of the so-called 'diagram efficiency' or utilization factor (in that the exhaust kinetic energy is used in most turbine stages). It is unfortunate that they do not develop definitions of turbine and compressor efficiency in terms of stagnation states, which are but briefly discussed in the section on isentropic flow.

It is pleasing to note that the heat transfer section is competently and thoroughly written.

If the division of the material into the four sections is somewhat artificial, if the book is a little too wordy and is slightly uneven (the omission of the subject of availability and the inclusion of detailed discussion of turbulent shear flows are examples of this), these are but very small criticisms in comparison with the fine overall achievement this book represents. The authors are to be congratulated on writing an excellent book, for student and teacher, and the publishers are to be congratulated on producing it at a reasonable price.
J. H. HORLOCK 